\author{
А.М. Вафин
}

\title{
ПОЛИТИЧЕСКАЯ МАРГИНАЛЬНОСТЬ: К ПРОБЛЕМЕ ТИПОЛОГИИ ПОЛИТИЧЕСКОГО ЛИДЕРСТВА
}

\begin{abstract}
Аннотация. В современной политической теории уже стала обычной фокусировка на таких темах, как политические системь, идеологии, политическое лидерство, однако иельй ряд подвопросов внутри этих тем не анализируется. К подобного рода подвопросам относится феномен политической маргинальности. В статье анализируется феномен политической маргинальности и лидерство политических маргиналов. Данный феномен характеризует оппозиционных лидеров, которые, либо стремятся ограничить свою оппозиционность, либо наоборот, вступают в конфронтацию с политической системой. Политическая психология предпочитает рассматривать политических лидеров уже в качестве состоявшихся системных политических агентов, даже несмотря на то, ито тидерскими качествами они могут не обладать. В статье дается типология лидерства политических маргиналов. Этого автор достигает за счет расширения грании политологии, обращаясь к современным наработкам организаиионной психологии по трансформационному лидерству, т.е. постоянно изменяющемуся, открытому изменениям лидерству. Трансформачионное лидерство символизирует такое поведение лидеров, которое мотивирует работников следовать организационным иелям и интересам. В результате анализа автор выделяет два типа лидеров: лидер-популист и идеологически ангажированный лидер.

Ключевые слова: манипулятивные идеологии, политическая психология, организационная психология, популизм, трансформационное лидерство, политическое лидерство, политическая маргинальность, харизма, лидер-популист, ангажированный лидер.
\end{abstract}

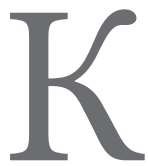
лассическая политическая наука (в рамках субдисциплины политическая психология) предпочитает рассматривать политических лидеров уже в качестве состоявшихся системных политических агентов, несмотря на то, что лидерскими качествами они могут не обладать ${ }^{1}$. Проблема такого подхода в том, что из политики, где есть место только для лидеров как руководителей (т.е. тех, кто обладает властью), исключаются политические лидеры, находящиеся вне политической системы. Получается, что в политике лидерами могут быть только руководители, включенные в политическую систему. Однако политика не ограничивается политической системой. Допустимо говорить о поле политики, в которое вписана политическая система ${ }^{2}$. Вне политической

1 Политический процесс: основные аспекты и способы анализа. М., 2001. С. 192.

2 Бурдье П. Социология политики. М., 1993. Политическая система - не категория Бурдье, однако можно утверждать, что она имплицитно присутствует в поле политики, той его институционализированной части, где политика является де- системы - но не вне политики, не вне политического пространства - существуют такие политические агенты, как политические маргиналы. Последние также могут являться политическими лидерами.

По вопросу лидерства и обладания ресурсом управления политологи расходятся во взглядах с учеными, которые занимаются организационной психологией ${ }^{3}$. Как отмечают М. Мескон, М. Альберт и Ф. Хедоури: «Управляющий (он же руководитель - A.B.) становится во главе организации в результате намеренного действия формальной организации - делегирования полномочий. Лидерами, с другой стороны, становятся не по воле организации», - т.е. подчеркивается некое формальное и неформальное различение. «Члены организации знают, кто их руководитель, а вот ведомые

лом государственным. В редуцированном виде политическая система тождественна совокупности институтов власти.

3 Уместно вспомнить и такой феномен, как конструирование лидерства: Вафин А. Идеология в организации: Психологические игры в «лидеров» и манипуляции «массами». М., 2013. 


\section{Психология масс}

не всегда знают, что их ведут» ${ }^{4},-$ делают важное дополнение авторы.

Используя логику организационной метафоры, можно выделить три типа макрополитических отношений: 1) opганизация есть партия гегемон, следовательно, только в ее формате возможны руководители и политические лидеры; 2) организация есть политическая система, действующая за счет управления элементами-членами, которые воплощаются в фигурах лидеров и руководителейㅎ 3 ) организация есть сложное синергетическое политическое пространство, где есть место лидерам и руководителям и в политической системе, и вне ее ${ }^{6}$. Если первый тип таких политических отношений характеризует тоталитарное общество, то второй и третий описывают как (пост)демократические, так и авторитарные общества.

Непосредственно в политологии одну из классических типологий политического лидерства ученые возводят к социологу М. Веберу. Исходя из концепции трех видов легитимации господства Вебера, политологи выделяют три типа лидерства: традиционное, рационально-легальное и харизматическое ${ }^{7}$ Лидерство нас интересует как социально-психологический феномен (это касается и харизмы), где индивидуальные качества человека влияют на общественные отношения, при этом находятся под их воздействием: «Хотя окружающая действительность репрезентирована каждому человеку в отдельности, формирование общей картины мира и “прорисовка" ее деталей осуществляется коллективно. В процессе общения вырабатываются единые для всех... типовые понятия и представления, благодаря которым, собственно, люди и понимают друг друга» ${ }^{8}$.

М. Бернс предложил две основные категории политических лидеров: преобразователей и дельцов. «Преобразователи предлагают свою модель общественного развития, дельцы ставят конкретные прагматические цели и вырабатывают механизмы их достижения. Для стабильной политической системы характерен “деловой” тип лидерства, а трансформирующейся - “преобразующий”»". Тем не менее, эта типология неспособна описать интересующий нас феномен лидерства политических маргиналов, опять

\footnotetext{
4 Мескон М.Х., Альберт М., Хедоури Ф. Основы менеджмента. М., 1998. С. 513.

5 Такое видение разделяют не только политики-практики, но и ученые политологи.

6 Вопрос о том, можно ли руководить политической системой находясь вне системы, оставим за скобками.

7 Политический процесс: основные аспекты и способы анализа. М., 2001. С. 202.

8 Андреев А. Политическая психология. М., 2002. С. 13.

9 Политический процесс: основные аспекты и способы анализа. М., 2001. С. 203.
}

же по той причине, что эта типология ориентирована на политическую систему, но не на то, что выходит за ее рамки. Российский автор Г. Авцинова предложила рассматривать политических лидеров с точки зрения властвования и оппозиции (но, к сожалению, опять в рамках властвования): «Оппозиционный (лидер - A.B.) делится на два подтипа конфронтационно-оппозиционный (непримиримый противник существующей власти) и конструктивно-оппозиционный (критикует существующую власть, но не ориентирован на ее немедленное свержение)». Что касается властвующих лидеров, то они представляют эгоцентрический и социоцентрический типы: «Лидер эгоцентрического типа... стремится к самореализации с помощью власти... Социоцентрический видит цель своей деятельности в выполнении общественного долга» ${ }^{10}$.

Политический маргинал - это оппозиционный лидер, который, либо стремится ограничить свою оппозиционность, либо наоборот, стремится перейти к конфронтации, уйти от конструктивного диалога. Мы можем говорить о следующих типах лидеров, в большей степени характерных для данного феномена: во-первых, это лидер-популист; во-вторых, это идеологически ангажированный политический лидер. Специально оговоримся, что лидер-популист и идеологически ангажированный политический лидер не являются некими сущностями, характерными только для политических маргиналов. Лидеров-популистов и идеологически ангажированных политических лидеров можно обнаружить и в респектабельных политических партиях, включенных в политическую систему. Тем не менее, лидер-популист и идеологически ангажированный политических лидер наиболее типичные случаи, характеризующие феномен политической маргинальности.

Учитывая ориентированность психологии лидерства на рационалистическую философию (извлечение максимальной прибыли при минимизации издержек), мы хотим предложить некоторую новацию, обратиться к современной теории организационной психологии, именуемую трансформационным лидерством. При его рассмотрении мы сошлемся на текст Дж. Сарроса, Б. Купера и Дж. Сантора.

Что такое трансформационное лидерство? Трансформационное лидерство (т.е. постоянно изменяющееся, открытое изменениям лидерство) символизирует такое поведение лидеров, которое мотивирует работников следовать организационным целям и интересам. Сами цели мотивируют (должны мотивировать) сотрудников на активную работу. Опираясь на П. Подсакоффа, С. МакКинзи, Р. Мурмана и Р. Феттера, Саррос и его соавторы отмечают, что трансформационное лидерство базируется

10 Там же. С. 203-204. 


\section{Психология и психотехника 9(60) • 2013}

на шести факторах: 1) видение будущего (миссии) организации, которое лидер четко артикулирует (это облегчает многие трудности, членам организации ясно, что от них хотят); 2) соответствие лидера роли лидера, а работников роли работников (члены организации видят, что лидер является настоящим лидером, а не сконструированным персонажем); 3) выдвижение целей (эти цели должны быть обязательно принимаемы и одобряемы членами организации); 4) исполнение ожиданий (это вытекает из миссии и целей организации, члены организации понимают, что то, к чему пришла организация, и есть то, что было необходимо в определенных условиях для конкретной ситуации); 5) индивидуальная поддержка (даже общаясь с группой, лидер нацелен на каждого); 6) интеллектуальное стимулирование членов организации ${ }^{11}$.

Подход Сарроса, Купера и Сантора держится не только на лидерстве, они дополняют его организационной культурой, которую можно интерпретировать как поведение индивидов в организации, подкрепленное верой в определенные ценности, сформулированные самой структурой ${ }^{12}$, что, несомненно, актуально и для политической действительности, в воплощении культуры в рамках политической идеологии. Данный подход привлекателен тем, что он не замыкается на одном лидере, а говорит о том, что в организации существуют и другие люди. Если перенести крайнюю форму такого бизнес-лидера в политическую среду, то в результате мы получим лидера популистского типа. В определенном смысле, такой лидер это лицо организации: «Персонализация власти, пишет М. Дюверже о партиях, - порой сопровождается настоящим ее обожествлением. Таким путем возрождается одна из древнейших форм авторитета - авторитета монарха-бога» ${ }^{13}$. Поэтому некоторые аналитики правых организаций допускают переход от анализа коллективного организма к анализу конкретного лидера ${ }^{14}$.

Популизм - феномен неоднозначный. Ученые понимают под популизмом и дискурс, и синдром, и стратегию,

11 Sarros J.C., Cooper B.K., Santora J.C. Building a Climate for Innovation Through Transformational Leadership and Organizational Culture // Journal of Leadership \& Organizational Studies. 2008. Vol. 15. № 2. P. 147.

12 Op. cit.

13 Дюверже М. Политические партии. М., 2007. С. 229.

14 См.: Умланд А. Три разновидности постсоветского фашизма. Концептуальные и контекстуальные проблемы интерпретации современного русского ультранационализма // Форум новейшей восточноевропейской истории и культуры. 2006. № 2 // URL: http://www1.ku-eichstaett.de/ZIMOS/forum/ docs/Umland6.pdf (27.05.2013). О возможностях метафорики индивидуального и коллективного тела в организационном контексте см.: Вафин А.М. Идентичность и тело организации: интеракционистский подход к организационной психологии // Психология и психотехника. 2012. № 3. и стиль, и идеологию. Идеально-типический популизм включает в себя: «теорию заговора, народный (folksy) стиль, мощный волюнтаризм, симпатию к плебисцитарной демократии и харизматическое лидерство» ${ }^{15}$. Также для популистов характерно пренебрежение установленным правом ${ }^{16}$, что привязывает их к манипулятивным идеологиям. Как отмечает российский политолог Аль-Дайни «манипулятивные идеологии отличаются эклектизмом, отсутствием стабильного идеологического ядра, стремлением постоянно приспосабливаться к массовым настроениям, отсутствием стабильной социальной базы, стремлением привлечь на свою сторону максимальное количество людей без учета дифференциации их настроений, а также стремлением маскировать истинные цели субъектов идеологического воздействия посредством мимикрии под другие идеологии или создания иллюзии “внеидеологичности” ${ }^{17}$. Однако здесь нет полного доминирования императивных технологий, здесь работают технологии влияния, базирующиеся на превосходстве в капиталах или харизме.

Лидер-популист - это человек с претензией на харизму, человек, который все время трансформируется и адаптируется к новым условиям. Как замечает М. Вебер, «особенностью Запада, что для нас более важно, является политический вождизм в образе сначала свободного “демагога”, существовавшего на почве города-государства, характерного только для Запада, и прежде всего для средиземноморской культуры, а затем - в образе парламентского “партийного вождя”, выросшего на почве конституционного государства, укорененного тоже лишь на Западе» ${ }^{18}$. По мнению итальянского политолога П. Помбени, «харизматический тип господства предполагается не для нормальной ситуации, а только для фазы "statu nascendi" (в состоянии зарождения). Потом должна наступить рационализация харизмы: хорошо известный процесс ее рутинизации (Veralltaglichung), когда она начинает передаваться в законной форме и приводит от «сообщества» избранных к “институту” (членами которого становятся по объективным причинам, независимо от каких-то личностных качеств)» ${ }^{19}$.

15 Vossen K. Populism in the Netherlands after Fortuyn: Rita Verdonk and Geert Wilders Compared // Perspectives on European Politics and Society. 2010. Vol. 11. № 1. P. 22-38.

16 Bernard C. Populism, Politics and Democracy // Democratization. 2005. Vol. 5. № 12. P. 625.

17 Отчет о заседании семинара «Политические идеи и идеологии в публичной сфере», Москва, 6 апреля 2011 г. Доклад M.A. Аль-Дайни. URL: http://rapn.ru/?grup=595\&doc $=3580$ (Дата обращения: 27.05.2013).

18 Вебер М. Политика как призвание и профессия // Вебер М. Избранные произведения. М., 1990. С. 647.

19 См.: Помбени П. Харизматическое лидерство между идеальным типом и идеологией (Реферат) // Политическая наука. 2009. № 4. С. 194-198. 
Отличия лидер-популиста и идеологически ангажированного лидера в том, что популист более гибок по отношению к тем ценностям и идеологиям, которые он представляет. Идеологически ангажированный лидер наиболее ригиден, его привязка к идеологическому ценностному ядру настолько сильна, что он не способен даже в тактических целях поступиться собственными принципами.

Политический маргинал как идеологически ангажированный лидер - это перманентный внесистемный политический агент, исключенный из политики, проводимой политической системой. Исходя из идей политического психолога Д. Ольшанского, популист и идеологически ангажированный лидер, это даже не столько лидеры, сколько вожди нового типа: «Вождь опирается на поддержку населением исключительно его личности. Лидер стремится опираться на поддержку его программы. Вождь стремится к тому, чтобы его любили. Лидеру важнее, чтобы его понимали... Лидерство и вождизм существуют в разных условиях» ${ }^{20}$. Во многом, вождь это фигура массового общества, немного напоминающее общество язычников, для которого персональное растворяется в фигуре лидера ${ }^{21}$. «Он (вождь - A.B.) превращает внушаемую толпу в коллективное движение, сплоченное одной верой, направляемое одной целью. Он - художник общественной жизни, и его искусство - правление... Именно он формирует массу, готовит ее к идее, которая наполнит ее плотью и кровью» ${ }^{22}$, — поэтически описывает эту фигуру социальный психолог С. Московичи.

С политическими маргиналами, являющимися идеологически ангажированными лидерами все более или менее понятно. Они малоизвестны или же утратили свой былой авторитет. Это не значит, что, будучи лидерами группускул ${ }^{23}$, они неспособны совершить масштабную провокацию или же выйти за пределы символической борьбы, тем самым перейдя к практике насилия. Так или иначе, таким политическим маргиналам невозможно войти в политическую систему. Куда интереснее политические маргиналы, являющиеся лидерами-популистами. Такие лидеры способны преодолеть свою маргинальность.

Приведем пример лидера-популиста П. Фортейна. «На первых голландских всеобщих выборах 2002 года Пим Фортейн не только создал новую партию, целиком построенную вокруг его личности, но и назвал ее своим именем («Спиоск Пима Фортейна») — и та добилась столь поразительных успехов, что продолжала существовать, даже несмотря на его убийство незадолго до выборов» ${ }^{24}$, отмечает социолог и политолог К. Крауч.

И. Бурума дает следующий социально-психологический портрет Фортейна. Фортейн - это человек с глубоким чувством обиды, которая проистекает из недовольства, возможно, из страха перед гомофобией, исходящей от некоторых мусульманских иммигрантских слоев. В 90-е Фортейн переехал из Гронингена в Роттердам, где стал профессором социологии: «Местная иммигрантская молодежь разбила окна бара Mateloos (роттердамский гей-бар - A.B.) и угрожала его клиентам. Фортейн внезапно почувствовал себя беззащитным в стране, которую всегда считал безопасной. Это сильно отразилось на его политическом мышлении». Аутсайдерство на почве гомосексуализма дополнялось завистью к людям, обладающим социальным статусом. Именно статусом, а не деньгами. Люди, которые потянулись к Фортейну в качестве спонсоров были похожи на него: «подержали его люди, сделавшие состояние, которое позволило им обрести дома и яхты, но не положение в обществе... Некоторые из них так и не избавились от криминального ореола» ${ }^{25}$.

За счет популистских качеств, харизмы и бунтарского флера Фортейн сумел сыграть на анти-иммигрантских настроениях, которые принесли ему небывалую популярность. Фортейну предсказывали будущее премьер-министра, однако смерть прервала его политическую карьеру.

\section{Список литературь:}

1. Андреев А. Политическая психология. М., 2002.

2. Бурдье П. Социология политики. М., 1993.

3. Бурума И. Убийство в Амстердаме: Смерть Тео ван Гога и границы толерантности. М., 2008.

4. Вафин А. Идентичность и тело организации: интеракционистский подход к организационной психологии // Психология и психотехника. 2012. № 3.

20 Ольшанский Д. Вожди и лидеры. Вождизм // URL: http:// psyfactor.org/lib/lider6.htm (Дата обращения: 27.05.2013).

21 Гуревич П.С. Куда идешь, человек? // Знание. 1991. № 7.

22 Московичи С. Наука о массах // Психология масс. Самаpa, 2010. C. 479.

23 См.: Гриффин Р. От слизевиков к ризоме: введение в теорию группускулярной правой // Верхи и низы русского национализма. М., 2007.

24 Крауч К. Постдемократия. М., 2010. С. 43.

25 Бурума И. Убийство в Амстердаме: Смерть Тео ван Гога и границы толерантности. М., 2008. С. 72, 79. 


\section{Психология и психотехника 9(6o) • 2013}

5. Вафин А. Идеология в организации: Психологические игры в «лидеров» и манипуляции «массами». М., 2013.

6. Вебер М. Политика как призвание и профессия // Вебер М. Избранные произведения. М., 1990.

7. Гриффин Р. От слизевиков к ризоме: введение в теорию группускулярной правой // Верхи и низы русского национализма. М., 2007.

8. Гуревич П.С. Куда идешь, человек? // Знание. 1991. № 7; Его же: Гуревич П.С. Философская интерпретация человека. М., 2013.

9. Дюверже М. Политические партии. М., 2007.

10. Крауч К. Постдемократия. М., 2010.

11. Мескон М.Х., Альберт М., Хедоури Ф. Основы менеджмента. М., 1998.

12. Московичи С. Наука о массах // Психология масс. Самара, 2010.

13. Ольшанский Д. Вожди и лидеры. Вождизм // URL: http://psyfactor.org/lib/lider6.htm (Дата обращения: 27.05.2013).

14. Отчет о заседании семинара «Политические идеи и идеологии в публичной сфере», Москва, 6 апреля 2011 г. Доклад М.А. Аль-Дайни // URL: http://rapn.ru/?grup=595\&doc=3580 (Дата обращения: 27.05.2013).

15. Политический процесс: основные аспекты и способы анализа. М., 2001.

16. Помбени П. Харизматическое лидерство между идеальным типом и идеологией (Реферат) // Политическая наука. 2009. № 4.

17. Умланд А. Три разновидности постсоветского фашизма. Концептуальные и контекстуальные проблемы интерпретации современного русского ультранационализма // Форум новейшей восточноевропейской истории и культуры. 2006. № 2 // URL: http://www1.ku-eichstaett.de/ZIMOS/forum/docs/Umland6.pdf (27.05.2013).

18. Bernard C. Populism, Politics and Democracy // Democratization. 2005. Vol. 5. № 12.

19. Sarros J.C., Cooper B.K., Santora J.C. Building a Climate for Innovation Through Transformational Leadership and Organizational Culture // Journal of Leadership \& Organizational Studies. 2008. Vol. 15. № 2.

20. Vossen K. Populism in the Netherlands after Fortuyn: Rita Verdonk and Geert Wilders Compared // Perspectives on European Politics and Society. 2010. Vol. 11. № 1.

\section{References (transliteration):}

1. Andreev A. Politicheskaya psihologiya. M., 2002.

2. Burd'e P. Sociologiya politiki. M., 1993.

3. Buruma I. Ubiystvo v Amsterdame: Smert' Teo van Goga i granicy tolerantnosti. M., 2008.

4. Vafin A. Identichnost' i telo organizacii: interakcionistskiy podhod k organizacionnoy psihologii // Psihologiya i psihotehnika. 2012. № 3.

5. Vafin A. Ideologiya v organizacii: Psihologicheskie igry v «liderov» i manipulyacii «massami». M., 2013.

6. Veber M. Politika kak prizvanie i professiya // Veber M. Izbrannye proizvedeniya. M., 1990.

7. Griffin R. Ot slizevikov k rizome: vvedenie v teoriyu gruppuskulyarnoy pravoy // Verhi i nizy russkogo nacionalizma. M., 2007.

8. Gurevich P.S. Kuda idesh, chelovek? // Znanie. 1991. № 7.

9. Dyuverzhe M. Politicheskie partii. M., 2007.

10. Krauch K. Postdemokratiya. M., 2010.

11. Meskon M.H., Al'bert M., Hedouri F. Osnovy menedzhmenta. M., 1998.

12. Moskovichi S. Nauka o massah // Psihologiya mass. Samara, 2010.

13. Ol'shanskiy D. Vozhdi i lidery. Vozhdizm. (URL: http://psyfactor.org/lib/lider6.htm (Data obrascheniya: 27.05.2013)).

14. Otchet o zasedanii seminara «Politicheskie idei i ideologii v publichnoy sfere», Moskva, 6 aprelya 2011 g. Doklad M.A. Al'-Dayni. (URL: http://rapn.ru/?grup=595\&doc=3580 (Data obrascheniya: 27.05.2013)).

15. Politicheskiy process: osnovnye aspekty i sposoby analiza. M., 2001.

16. Pombeni P. Harizmaticheskoe liderstvo mezhdu ideal'nym tipom i ideologiey (Referat) // Politicheskaya nauka. 2009. № 4.

17. Umland A. Tri raznovidnosti postsovetskogo fashizma. Konceptual'nye i kontekstual'nye problemy interpretacii sovremennogo russkogo ul'tranacionalizma // Forum noveyshey vostochnoevropeyskoy istorii i kul'tury. 2006. № 2. (URL: http://www1.ku-eichstaett.de/ZIMOS/forum/docs/Umland6.pdf (27.05.2013)).

18. Bernard C. Populism, Politics and Democracy // Democratization. 2005. Vol. 5. № 12.

19. Sarros J.C., Cooper B.K., Santora J.C. Building a Climate for Innovation Through Transformational Leadership and Organizational Culture // Journal of Leadership \& Organizational Studies. 2008. Vol. 15. № 2.

20. Vossen K. Populism in the Netherlands after Fortuyn: Rita Verdonk and Geert Wilders Compared // Perspectives on European Politics and Society. 2010. Vol. 11. № 1. 